\title{
Pengaruh Bimbingan Kelompok Terhadap Motivasi Belajar Siswa \\ Di SMA Negeri 2 Kota Bima
}

\author{
Alya Nurmaya \\ STKIP BIMA \\ email: alyabinsyeikhabubakar@gmail.com
}

\begin{abstract}
Abstrak
Di lingkungan SMA Negeri 2 Kota Bima siswa dituntut mampu belajar dengan tekun sesuai dengan aturan yang ada di sekolah, sehingga dengan diberikan bimbingan kelompok memungkinkan siswa Kelas XI di SMA Negeri 2 Kota Bima, meningkatkan motivasi untuk belajar. Dan dengan adanya bimbingan kelompok akan memberikan bantuan kepada siswa melalui kegiatan bimbingan kelompok. Dalam bimbingan kelompok ini merupakan sarana untuk menunjang perkembangan optimal masing-masing siswa, yang diharapkan dapat mengambil manfaat. Artinya semua peserta dalam kegiatan kelompok saling berinteraksi, bebas mengeluarkan pendapat, menanggapi, memberi saran, dan kritik. Apa yang dibicarakan itu semuanya bermanfaat untuk diri peserta yang bersangkutan dan untuk peserta lainnya.

Dengan adanya bimbingan kelompok di SMA Negeri 2 Kota Bima, sangat positif sekali sehingga motivasi belajar siswa yang peneliti lihat sangat realatif. Adapun upaya untuk membantu individu agar dapat mencapai perkembangan secara optimal sesuai dengan kemampuan bakat dan minat yang ada dan untuk mengambil manfaat dari hasil kegiatan tesebut. Rumusan masalah dalam penelitian ini adalah sebagai berikut: Apaka ada pengaruh bimbingan kelompok terhadap motivasi belajaran siswa di SMA Negeri 2 Kota Bima Tahun 2016-2017. Dari rumusan masalah di atas, maka tujuan yang ingin dicapai dalam penelitian ini adalah untuk mengetahui besarnya pengaruh bimbingan kelompok terhadap motivasi belajar siswa Kelas XI di SMA Negeri 2 Kota Bima tahun ajaran 2016/2017. Adapun ruang lingkup dalam penelitian ini adalah sebagai berikut: 1) Penentuan variabel: bimbingan kelompok sebagai variabel X (variabel bebas) dan motivasi belajar sebagai variabel Y (variabel terikat); 2) Subjek Penelitian: siswa Kelas XI di SMA Negeri 2 Kota Bima. 3) Obyek penelitian adalah bimbingan kelompok. 4) Lokasi penelitian di SMA Negeri 2 Kota Bima. Dalam penelitian ini penulis menggunakan rancangan penelitian kuantitatif empirik. Populasi penelitian lebih dari 100 maka peneliti membatasi sampel dalam penelitian ini adalah sebanyak $10 \%$ dari seluruh populasi penelitian, sehingga sampel dari penelitian ini adalah 35 orang siswa kelas X SMAN 2 Kota Bima. Adapun tehnik analisis data penelitian ini digunakan analisis regresi linear sederhana untuk menganalisis data tentang pengaruh bimbingan kelompok terhadap motivasi belajar siswa di SMAN 2 Kota Bima dengan rumus: $Y^{\prime}=a+b X$.

Berdasarkan hasil wawancara dan observasi selama penelitian dilaksanakan diperoleh kesimpulan bahwa ada pengaruh bimbingan kelompok pada mata pelajaran matematika terhadap motivasi belajar siswa di SMAN 2 KotaBima Tahun Pelajaran 2016/2017, hal ini dibuktikan dari hasil analisis data menggunakan analisis regresi yang menandakan hubungan antara kedua variabel yang terlibat adalah positif dengan $Y=33,196-51,26 x$ yang artinya antara kedua variabel yang terlibat berhubungan positif.

Kata Kunci: Bimbingan kelompok, motivasi belajar.
\end{abstract}

\section{PENDAHULUAN}

Dalam Undang-Undang No. 20 tahun 2003 tentang sistem pendidikan nasional pasal 3 menjelaskan bahwa pendidikan nasional berfungsi mengembangkan kemampuan dan membentuk manusia indonesia yang bermartabat dalam rangka mencerdaskan kehidupan bangsa, bertujuan untuk mengembangkan potensi peserta didik agar menjadi manusia yang beriman dan bertaqwa kepada Tuhan

Alya Nurmaya

Konseling Keluarga dalam Seting Kehidupan Keluarga (Aplikasi

Pendekatan Sistem, Logo Terapi dan Perilaku)
Jurnal Guiding World

Vol. 2 No. 1. Mei 2019 
Yang Maha Esa, berakhlak mulia, sehat, berilmu, cakap, kreatif, mandiri dan menjadi warga negara yang demokratis serta bertanggung jawab. Tujuan dengan adanya bimbingan kelompok di SMA Negeri 2 Kota Bima akan meningkatkan motivasi belajar pada siswa. Kegiatan membimbing siswa untuk dapat mengembangkan diri secara optimal sesuai dengan tahap perkembangan dan tuntutan lingkungan yang positif, terutama dalam meningkatkan motivasi belajar siswa. Di lingkungan SMA Negeri 2 Kota Bima siswa dituntut mampu belajar dengan tekun sesuai dengan aturan yang ada di sekolah, sehingga dengan diberikan bimbingan kelompok memungkinkan siswa Kelas XI di SMA Negeri 2 Kota Bima, meningkatkan motivasi untuk belajar. Dengan adanya bimbingan kelompok ini merupakan sarana untuk menunjang perkembangan optimal masing-masing siswa, yang diharapkan dapat mengambil manfaat. Artinya semua peserta dalam kegiatan kelompok saling berinteraksi, bebas mengeluarkan pendapat, menanggapi, memberi saran, dan kritik. Apa yang dibicarakan itu semuanya bermanfaat untuk diri peserta yang bersangkutan dan untuk peserta lainya yang ada di SMA Negeri 2 Kota Bima. Dengan adanya bimbingan kelompok di SMA Negeri 2 Kota Bima, sangat positif sekali sehingga motivasi belajar siswa yang peneliti lihat sangat realatif. Adapun upaya untuk membantu individu agar dapat mencapai perkembangan secara optimal sesuai dengan kemampuan bakat dan minat yang ada dan untuk mengambil manfaat dari hasil kegiatan tesebut.

Berdasarkan uraian latar belakang di atas, dapat dirumuskan permasalahan sebagai berikut: Apakah ada pengaruh bimbingan kelompok terhadap motivasi belajaran siswa Kelas XI di SMA Negeri 2 Kota Bima Tahun 2016/2017.

Dari rumusan masalah di atas, maka tujuan yang ingin dicapai dalam penelitian ini adalah: Untuk mengetahui besarnya pengaruh bimbingan kelompok terhadap motivasi belajar siswa Kelas XI di SMA Negeri 2 Kota Bima tahun ajaran 2016/2017. Adapun hipotesis yang diajukan dalam penelitian ini adalah hipotesis alternatif (Ha) yang berbunyi: Ada pengaruh positif bimbingan kelompok terhadap motivasi belajar pada siswa kelas XI di SMA Negeri 2 Kota Bima tahun pelajaran 2016/2017. Adapun ruang lingkup penelitian ini adalah sebagai berikut: 1) Penentuan variabel: Bimbingan Kelompok sebagai variabel X (variabel bebas) dan motivasi belajar sebagai variabel Y (variabel terikat): Subjek Penelitian: siswa Kelas XI di SMA Negeri 2 Kota Bima Tahun Pelajaran 2016/2017; Obyek penelitian adalah bimbingan kelompok; Lokasi penelitian di SMA Negeri 2 Kota Bima.

Untuk menghindari kesalahan dalam penafsiran maka perlu dijelaskan definisi operasional variabel bimbingan kelompok dan motivasi belajar:

a. Bimbingan Kelompok

Bimbingan kelompok adalah suatu kegiatan kelompok yang dilakukan oleh sekelompok orang dengan memanfaatkan dinamika kelompok yaitu adanya interaksi saling mengeluarkan pendapat, memberikan tanggapan, saran, dan sebagainya, dimana pemimpin kelompok menyediakan informasiinformasi yang bermanfaat agar dapat membantu individu mencapai perkembangan yang lebih optimal dalam mata pelajaran matematika.

b. Motivasi Belajar

Motivasi belajar adalah keseluruhan daya penggerak di dalam diri siswa yang menimbulkan kegiatan belajar yang menjamin kelangsungan dan memberikan arahan pada kegiatan belajar sehingga tujuan yang dikehendaki dapat tercapai baik yang berasal dari motivasi internal maupun external.

\section{KAJIAN PUSTAKA}

1. Tinjauan tentang Bimbingan Kelompok

a. Pengertian Bimbingan Kelompok

Bimbingan kelompok adalah bantuan terhadap individu yang dilaksanakan dalam situasi kelompok. Apa yang dibicarakan itu semuanya bermanfaat untuk diri peserta yang bersangkutan sendiri dan untuk 
peserta lainnya (Nurihsan, 2009: 23). Sedangkan dalam sumber lain dijelaskan bahwa bimbingan kelompok merupakan salah satu tehnik bimbingan yang berusaha membantu individu agar dapat mencapai perkembangannya secara optimal sesuai dengan kemampuan, bakat, minat, serta nilai-nilai yang dianutnya dan dilaksanakan dalam situasi kelompok. Bimbingan kelompok ditujukan untuk mencegah timbulnya masalah pada siswa yang mengembangkan potensi siswa (Romlah, 2001:3). Demikian juga hal yang senada dijelaskan bahwa bimbingan dimaksudkan untuk memungkinkan siswa secara bersama-sama memperoleh berbagai bahan dari nara sumber (terutama guru pembimbing) yang bermanfaat untuk kehidupan sehari-hari baik sebagai individu maupun sebagai pelajar, anggota keluarga dan masyarakat (Sukardi, 2003: 48).

Sedangkan bimbingan kelompok adalah suatu kegiatan kelompok dimana pemimpin kelompok menyediakan informasi-informasi dan mengarahkan diskusi agar anggota kelompok menjadi lebih sosial atau untuk membantu anggota-anggota kelompok untuk mencapai tujuaan bersama (Wibowo, 2005:17).

Dapat di simpulkan oleh peneliti bimbingan kelompok dalam mata pelajaran matematika di sekolah adalah suatu kegiatan kelompok yang dilakukan oleh sekelompok orang dengan memanfaatkan dinamika kelompok yaitu adanya interaksi saling mengeluarkan pendapat, memberikan tanggapan, saran, dan sebagainya, dimana pemimpin kelompok menyediakan informasi-informasi yang bermanfaat agar dapat membantu individu mencapai perkembangan yang lebih optimal dalam mata pelajaran matematika.

b. Asas-asas Bimbingan Kelompok

Dalam bimbingan kelompok ada beberapa azas, yaitu:, 1) Asas keterbukaan, 2) Asas kesukarelaan, 3) Asas kenormatifan (Prayitno, 2004: 114).

\section{c. Ciri-Ciri Bimbingan Kelompok}

Para ahli menyebut lima ciri-ciri yang hendaknya diperhatikan dalam menilai apakah kehidupan sebuah kelompok adalah baik atau kurang baik, kelima hal tersebut adalah: 1) Menjalin hubungan yang dinamis antara anggota, 2) Tujuan bersama, 3) Hubungan antara besarnya kelompok (banyak anggota) dengan sifat kegiatan kelompok, 4) Itikad dan sikap terhadap orang lain, dan 5) Kemampuan mandiri (Prayitno, 2001: 42).

\section{d. Evaluasi Kegiatan Layanan Bimbingan Kelompok}

Penilaian atau evaluasi kegiatan bimbingan kelompok di orientasikan kepada perkembangan pribadi siswa dan hal-hal yang dirasakan oleh anggota berguna.Penilaian kegiatan bimbingan kelompok dapat dilakukan secara tertulis, baik melalui essai, daftar cek, maupun daftar isian sederhana (Prayitno, 2001: 81).

Penilaian atau evaluasi hasil dari kegiatan layanan bimbingan kelompok ini bertitik tolak bukan pada kriteria "benar atau salah", tetapi berorientasi pada perkembangan, yakni mengenali kemajuan atau perkembangan positif yang terjadi pada diri anggota kelompok. Penilaian terhadap bimbingan kelompok dapat dilakukan melalui: a) Mengamati dan partisipasi dan aktifitas peserta selama kegiatan berlangsung, b) Mengungkapkan pemahaman peserta atas materi yang dibahas, c) Mengungkapkan kegunaan layanan bagi anggota kelompok, dan perolehan anggota sebagai hasil dari keikutsertaan mereka, d) Mengungkapkan minat dan sikap anggota kelompok tentang kemungkinan kegiatan lanjutan, e) Mengungkapkan tentang kelancaran proses dan suasana penyelengaraan layanan (Prayitno, 2005: 81).

\section{e. Tekhnik-tekhnik Bimbingan Kelompok}

Tekhnik dalam bimbingan kelompok menggunakan teknik umum atau disebut juga "tiga M", yaitu mendengar dengan baik, memahami secara penuh, dan merespon secara tepat dan positif. Kemudian pemberian dorongan minimal dan kenyataan. Selain itu, guru pembimbing secara langsung berada dalam 
kelompok tersebut, dan bertindak sebagai fasilitator (Pemimpin kelompok) dalam dinamika kelompok yang terjadi dengan menerapkan tekhnik-tekhnik bimbingan kelompok tersebut di atas.

\section{f. Kriteria Bimbingan Kelompok yang Efektif}

Bimbingan kelompok merupakan suatu sistem yang terdiri dari komponen yang saling berkaitan. Dapat terlaksana secara efektif dan efisien jika semua komponen dalam sistem tersebut mengarah pada perubahan dan pada suatu yang positif. Komponen sistem dalam bimbingan kelompok menurut Wibowo (2005: 189) adalah: "variabel raw input (siswa / anggota kelompok), instrumental input (konselor, program, tahapan dan sarana), enxiromental input (norma, tujuan dan lingkungan), proses atau perantara (interaksi, perlakuan kontrak keterampilan yang di sepakati akan diubah dan dinamika kelompok), output yaitu berkenaan dengan perubahan keterampilan atau penguasaan tugas-tugas".

2. Tinjauan tentang Motivasi Belajar

a. Pengertian Motivasi Belajar

Motivasi belajar menurut (Dimyati, 2006: 80), adalah kekuatan mental seseorang yang menjadi penggerak dalam belajar. Sedangkan menurut (Sobur, 2003: 267), motivasi belajar adalah dorongan, hasrat, keinginan dan tenaga penggerak lainnya yang berasal dari dalam diri untuk melakukan sesuatu, dan menurut (Manulang, 2007:18), motivasi belajar adalah hal yang menimbulkan dorongan. Artinya, motivasi belajar merupakan proses psikologis yang dapat menjelaskan perilaku seseorang.

Dari pendapat para ahli di atas dapat disimpulkan bahwa motivasi belajar merupakan suatu proses yang dapat menampilkan prilaku untk mencapai tujuan dalam memuaskan kebutuhan dirinyabaik motivasi inernal maupun external untuk mencapai tujuannya.

b. Faktor-faktor yang mempengaruhi Motivasi Belajar

Dalam kegiatan belajar mengajar peranan motivasi sangat diperlukan, motivasi bagi siswa dapat mengembangkan aktifitas dan inisiatif, dapat mengarahkan memelihara ketekunan dalam melakukan kegiatan belajar. Dalam kaitannya dengan itu perlu diketahui ada beberapa faktor yang dapat mempengaruhi motivasi belajar, yaitu: a) faktor kematangan, b) usaha yang bertujuan, c) pengetahuan mengenai hasil dalam motivasi, d) partisipasi, dan e) pengharapan dengan hukuman. Motivasi external adalah motivasi kecendrungan ketergantungan anak didik terhadap segala sesuatu diluar dirinya, anak didik yang belajar berdasarkan motivasi external sangat sedikit terpengaruh dari luar, semangat belajar sangat kuat (Sardiman, 2010: 93).

\section{c. Macam-macam Motivasi Belajar}

Secara umum motivasi belajar ada beberapa macam, yaitu: Motivasi Intrinsik merupakan motifmotif yang menjadi aktif atau berfungsinya tidak perlu dirangsang dari luar karena dalam setiap diri individu sudah ada dorongan untuk melakukan sesuatu (Djamarah, 2011:149). Sedangkan dalam sumber yang lain dikatakan bahwa motivasi intrinsik adalah ingin mencapai tujuan yang terkandung di dalam pembuatan belajar itu sendiri (Sardiman 2010: 90). Motivasi intrinsik yang dimiliki oleh setiap orang, tentu dengan tingkatan yang tidak sama tergantung kepada individu itu sendiri.

Berdasarkan pendapat ahli di atas, dapat disimpulkan oleh peneliti bahwa bila seseorang telah memiliki motivasi instrinsik dalam dirinya maka secara sadar akan melakukan suatu kegiatan yang tidak memerlukan motivasi dari luar dirinya, seseorang yang memiliki motivasi instrinsik selalu ingin mencapai tujuan dalam belajar.

d. Prinsip-prinsip Motivasi Belajar

Prinsip-prinsip tersebut adalah:

(1). Motivasi sebagai dasar penggerak yang mendorong aktifitas belajar. 
(2). Motivasi intrinsik lebih utama daripada motivasi ekstrinsik dalam belajar.

(3). Motivasi berupa pujian lebih baik dari pada hukuman.

(4). Motivasi berhubungan erat dengan kebutuhan dalam belajar.

e. Ciri-ciri Motivasi Belajar

Menurut Sardiman Sardiman dalam Tekun menghadapi tugas (dapat bekerja terus menerus dalam waktu yang lama, tidak pernah berhenti sebelum selesai).

(1) Ulet menghadapi kesulitan (tidak lekas putus asa).

(2) Menunjukkan minat terhadap bermacam-macam masalah (minat untuk sukses).

(3) Mempunyai orientasi ke masa depan.

(4) Lebih senang bekerja mandiri.

(5)Cepat bosan pada tugas-tugas yang rutin (hal-hal yang bersifat mekanis, berulang-ulang begitu saja sehingga kurang kreatif).

(6) Dapat mempertahankan pendapatnya (kalau sudah yakin akan sesuatu).

(7) Tidak pernah mudah melepaskan hal yang sudah diyakini.

(8) Senang mencari dan memecahkan masalah soal-soal.

f. Bentuk-bentuk Motivasi Belajar

Adapun bentuk-bentuk pentingnya motivasi belajar menurut (Djamarah, 2011: 158) adalah sebagai berikut: a) memberi angka, b) hadiah (c) kompetisi dan (d) pujian (Djamarah, 2011: 41).

3. Pengaruh Bimbingan Kelompok terhadap Motivasi Belajar Siswa

Bimbingan kelompok memberikan pengaruh terhadap motivasi belajar siswa. Melalui dinamika kelompok tersebut diharapkan masing-masing anggota memperoleh informasi atau topik-topik yang dibahas bersama, serta pengetahuan dan pengalaman yang penting dapat dikembangkan secara optimal sesuai dengan tugas perkembangan yang seharusnya dilaksanakan. Tujuan bimbingan kelompok diantaranya adalah setiap anggota kelompok mampu mengeluarkan pendapat, ide, saran, tanggapan, perasaan dan lain sebagainya, mampu berbicara di depan orang banyak, belajar menghargai pendapat orang lain, menjadi akrab satu sama lainnya, mampu mengendalikan diri dan dapat bertenggang rasa, berarti siswa akan dapat dengan mudah bersosialisasi, mudah memperoleh pemahaman dalam pembelajaran di sekolah, dapat mengembangkan pengetahuannya, yakni belajar dari pengalamannya, maupun melalui informasi yang mereka terima dari lingkungannya. Secara otomatis siswa telah memiliki motivasi belajar yang baik.

\section{METODOLOGI PENELITIAN}

\section{A. Rancangan Penelitian}

Dalam penelitian ini penulis menggunakan rancangan penelitian empirik, dalam hal ini yang berkaitan dengan pengaruh bimbingan kelompok terhadap motivasi belajar siswa SMAN 2 Kota Bima Tahun Pelajaran 2016/2017.

Adapun gambaran tentang rancangan penelitian ini dapat digambarkan sebagai berikut:

$$
\begin{gathered}
\text { Siswa SMAN } 2 \text { Kota } \\
\text { Bima }
\end{gathered}
$$




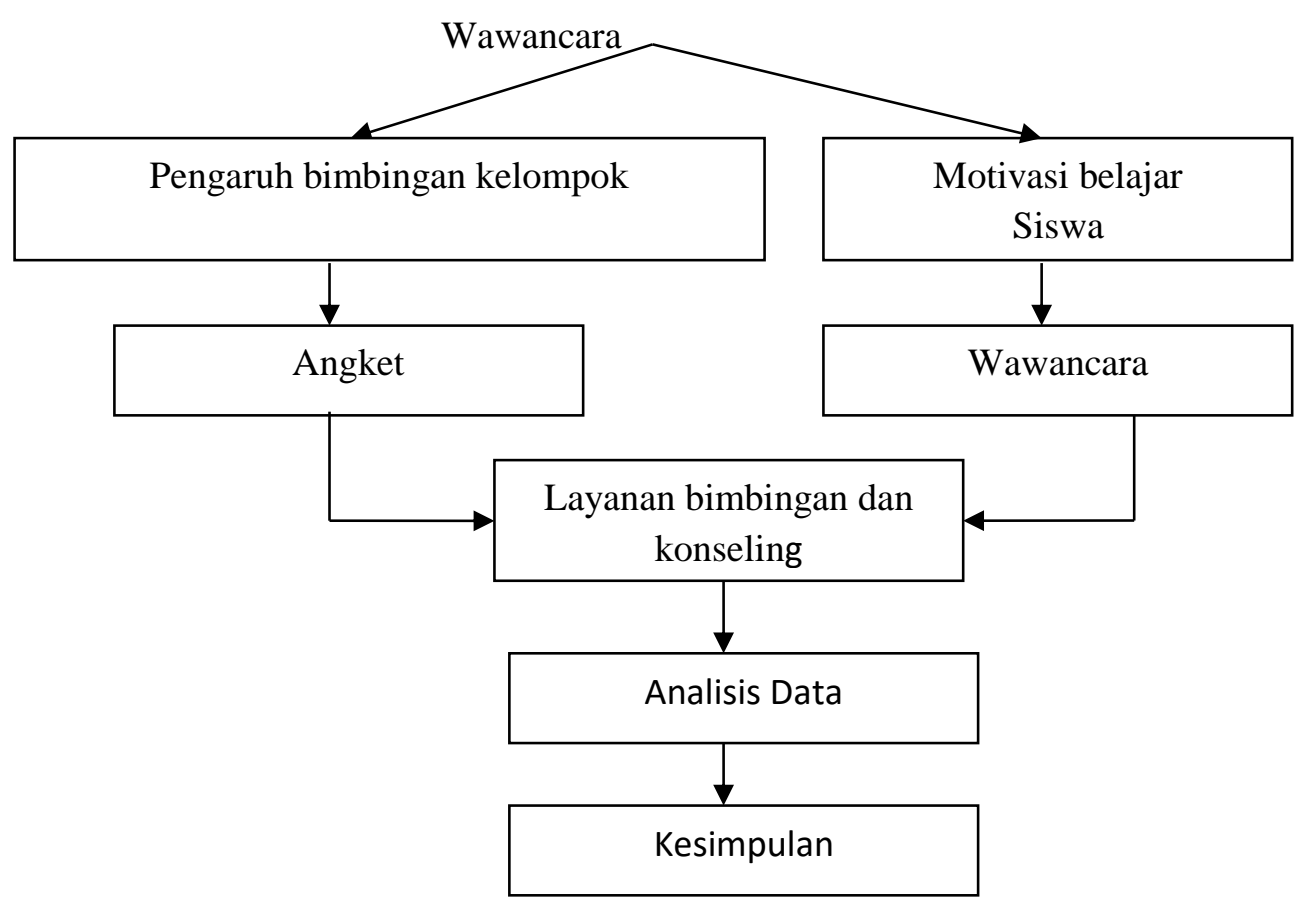

Gambar 3.1 Skema kerangka pikir (alur penelitian)

B. Populasi dan Sampel

Populasi yang diambil dalam penelitian ini adalah semua siswa kelas X SMAN 2 Kota Bima dengan jumlah siswa 350 orang. Karena populasi penelitian lebih dari 100 maka peneliti membatasi sampel dalam penelitian ini adalah sebanyak $10 \%$ dari seluruh populasi penelitian, sehingga sampel dari penelitian ini adalah 35 orang siswa kelas X SMAN 2 Kota Bima.

C. Instrumen Penelitian

Instrumen penelitian adalah alat yang dipergunakan pada waktu penelitian untuk mendapatkan data yang diperlukan. Adapun instrumen yang dikembangkan dalam penelitian ini adalah sebagai berikut:

1. Angket Penelitian

Adapun jumlah item angket sejumlah 10 butir untuk variabel bimbingan kelompok dan 10 butir untuk variabel motivasi belajar dengan masing-masing 5 pilihan jawaban dengan pedoman penskoran sebagai berikut: jawaban a dengan skor 5, jawaban b skor 4, jawaban c skor 3, jawaban d skor 2 dan jawaban e skor 1. Adapun kisi-kisi angket sebagai berikut:

Tabel 3.1 Kisi-Kisi Angket penelitian

\begin{tabular}{|l|l|l|l|l|}
\hline No & Variabel & Indikator & Sub Indikator & Item \\
& & & Soal \\
\hline
\end{tabular}




\begin{tabular}{|c|c|c|c|c|}
\hline \multirow[t]{3}{*}{1} & \multirow[t]{3}{*}{$\begin{array}{l}\text { Bimbingan } \\
\text { kelompok }\end{array}$} & $\begin{array}{l}\text { Siswa senang menerima } \\
\text { bimbingan kelompok }\end{array}$ & $\begin{array}{l}\text { Saling mempengaruhi antar } \\
\text { kelompok } \\
\text { Ada struktur yang mengatur pola } \\
\text { tingkah laku kelompok } \\
\text { Ada pengembangan standar nilai }\end{array}$ & 2 \\
\hline & & $\begin{array}{l}\text { Suasana Kelompok yang } \\
\text { hidup }\end{array}$ & $\begin{array}{l}\text { Ada kekompakan } \\
\text { Ada daya tarik } \\
\text { Ada motivasi } \\
\text { Ada hubungan interpersonal antar } \\
\text { kelompok }\end{array}$ & $\begin{array}{l}4 \\
5 \\
6 \\
7\end{array}$ \\
\hline & & $\begin{array}{l}\text { Proses kegiatan kelompok } \\
\text { dinamis }\end{array}$ & $\begin{array}{l}\text { Ada tujuan bersama } \\
\text { Ada tujuan bimbingan kelompok } \\
\text { Ada hubungan dengan cara belajar } \\
\text { Terjadi dinamika kelompok }\end{array}$ & $\begin{array}{l}8 \\
9 \\
10 \\
11\end{array}$ \\
\hline \multirow[t]{3}{*}{2} & \multirow[t]{3}{*}{$\begin{array}{l}\text { Motivasi } \\
\text { Belajar }\end{array}$} & $\begin{array}{l}\text { Memiliki kompetensi } \\
\text { (kemampuan Dalam diri) }\end{array}$ & $\begin{array}{l}\text { Prestasi belajar yang baik } \\
\text { Memiliki teman bergaul yang } \\
\text { banyak } \\
\text { Memiliki keterampilan tertentu }\end{array}$ & $\begin{array}{l}12 \\
13\end{array}$ \\
\hline & & $\begin{array}{l}\text { Berfikir positif terhadap } \\
\text { segala hal }\end{array}$ & $\begin{array}{l}\text { Menganggap orang lain sahabat } \\
\text { Menganggap semua pelajaran } \\
\text { adalah baik } \\
\text { Menganggap guru tidak ada yang } \\
\text { judes }\end{array}$ & $\begin{array}{l}16 \\
17\end{array}$ \\
\hline & & $\begin{array}{l}\text { Mandiri di dalam segala } \\
\text { pekerjaan }\end{array}$ & $\begin{array}{l}\text { Mampu mengerjakan tugas tampa } \\
\text { bantuan orang lain } \\
\text { Tidak bergantung pada orang lain }\end{array}$ & $\begin{array}{l}18 \\
19\end{array}$ \\
\hline
\end{tabular}




\begin{tabular}{|l|l|l|c|}
\hline & & $\begin{array}{l}\text { Tidak mencontek pekerjaan teman } \\
\text { Mengerjakan segala kebutuhan } \\
\text { sendiri }\end{array}$ & 21 \\
\cline { 2 - 4 } & Optimis & $\begin{array}{l}\text { Mempunyai cita-cita tinggi } \\
\text { Memiliki kemampuan dalam } \\
\text { pelajaran } \\
\text { Merasa segala perbuatannya adalah } \\
\text { yang }\end{array}$ & 22 \\
\hline
\end{tabular}

2. Pedoman Wawancara

\section{Tehnik Pengumpulan Data}

\section{Angket}

Penelitian ini menggunakan angket secara tertutup. Dengan angket tertutup dimaksudkan agar memperoleh jawaban yang sesuai oleh responden dan dengan alternatif jawaban yang telah tersedia. Instrumen atau alat yang dilibatkan adalah sejumlah pertanyaan tertulis yang siap diisi oleh responden. Adapun jumlah item angket sejumlah 12 butir untuk variabel bimbingan kelompok dan 12 butir soal untuk variabel motivasi belajar siswa, dengan metode penilaian sebagai berikut:

Untuk memperoleh data tentang bimbingan kelompok dilakukan penyebaran angket penelitian. Angket ini merupakan angket yang bersifat tertutup, sedangkan jumlah item dari angket tersebut adalah sebanyak 12 item. Adapun yang diberi nilai dari masing-masing item pada angket adalah sub a, b, c, d dan e. Untuk menilai hasil ini digunakan kriteria sebagai berikut:

Jawaban a diberi nilai 5 (lima), Jawaban b diberi nilai 4 (empat), Jawaban c diberi nilai 3 (tiga), Jawaban d diberi nilai 2 (dua), Jawaban e diberi nilai 1 (satu).

Demikian juga halnya dengan data tentang motivasi siswa dilakukan penyebaran angket penelitian. Angket ini merupakan angket yang bersifat tertutup pula, jumlah item dari angket tersebut adalah sebanyak 12 item. Adapun yang diberi nilai dari masing-masing item pada angket adalah sub a, b, c, d dan e. Untuk menilai hasil ini digunakan kriteria sebagai berikut:

Jawaban a diberi nilai 5 (lima), Jawaban b diberi nilai 4 (empat), Jawaban c diberi nilai 3 (tiga), Jawaban d diberi nilai 2 (dua), Jawaban e diberi nilai 1 (satu).

2. Wawancara 


\section{Tehnik Analisis Data}

Adapun tehnik analisis data penelitian ini digunakan analisis regresi linear sederhana untuk menganalisis data dan tentang pengaruh bimbingan kelompok terhadap motivasi belajar siswa di SMAN 2 Kota Bima dengan rumus:

$$
\mathrm{Y}^{\prime}=\mathrm{a}+\mathrm{bX}(\text { Sudijono, 1991:244) }
$$

Keterangan :

a $\quad=$ Y pintasan (nilai $\mathrm{y}^{\prime}$ bila $\mathrm{X}=0$ )

$\mathrm{b} \quad=$ kemiringan dari garis regresi

$\mathrm{X}=$ nilai variabel bebas

$\mathrm{Y}^{\prime} \quad$ = nilai yang diukur/dihitung pada variabel tidak bebas

\section{HASIL PENELITIAN DAN PEMBAHASAN}

Adapun data yang diperlukan dari siswa dalam penelitian ini adalah data tentang siswa SMAN 2

Kota Bima tahun pelajaran 2016/2017 sebagai berikut:

Tabel 4.1 Data siswa SMAN 2 Kota Bima yang dijadikan Sampel Penelitian

\begin{tabular}{|c|l|r|r|c|}
\hline No & \multicolumn{1}{|c|}{ Nama } & Nis & L/P & Kelas \\
\hline 1 & AW & 3608 & $\mathrm{~L}$ & $\mathrm{X} 1$ \\
\hline 2 & AS & 3615 & $\mathrm{~L}$ & $\mathrm{X} 1$ \\
\hline 3 & AM & 3618 & $\mathrm{~L}$ & $\mathrm{X} 1$ \\
\hline 4 & AI & 3623 & $\mathrm{P}$ & $\mathrm{X} 1$ \\
\hline 5 & DS & 3622 & $\mathrm{~L}$ & $\mathrm{X} 1$ \\
\hline 6 & DY & 3662 & $\mathrm{P}$ & $\mathrm{X} 1$ \\
\hline 7 & FH & 3633 & $\mathrm{~L}$ & $\mathrm{X} 1$ \\
\hline 8 & FA & 3770 & $\mathrm{P}$ & $\mathrm{X} 2$ \\
\hline 9 & FI & 3639 & $\mathrm{~L}$ & $\mathrm{X} 2$ \\
\hline
\end{tabular}

9 


\begin{tabular}{|c|c|c|c|c|}
\hline 10 & FS & 3648 & $\mathrm{P}$ & X 2 \\
\hline 11 & FAD & 3771 & $P$ & $\mathrm{X} 2$ \\
\hline 12 & IR & 3658 & $\mathrm{P}$ & X 2 \\
\hline 13 & IKP & 3814 & L & X 2 \\
\hline 14 & JI & 3665 & $P$ & X2 \\
\hline 15 & $\mathrm{JN}$ & 3676 & L & X2 \\
\hline 16 & KF & 3677 & $\mathrm{~L}$ & $\mathrm{X} 2$ \\
\hline 17 & KI & 3705 & $\mathrm{P}$ & $\mathrm{X} 2$ \\
\hline 18 & MF & 3692 & L & X 2 \\
\hline 19 & MA & 3701 & $\mathrm{P}$ & $\mathrm{X} 2$ \\
\hline 20 & MN & 3710 & L & X 2 \\
\hline 21 & MR & 3717 & $\mathrm{~L}$ & X 3 \\
\hline 22 & MRL & 3718 & $\mathrm{~L}$ & X 3 \\
\hline 23 & NI & 3724 & $P$ & X 3 \\
\hline 24 & $\mathrm{NH}$ & 3725 & $P$ & X 3 \\
\hline 25 & NRI & 3735 & $\mathrm{P}$ & X 3 \\
\hline 26 & RAH & 3742 & $\mathrm{P}$ & X 3 \\
\hline 27 & RFI & 3745 & $P$ & X 3 \\
\hline 28 & RDI & 3747 & $\mathrm{~L}$ & X 3 \\
\hline 29 & SRH & 3751 & $P$ & X 3 \\
\hline 30 & SRN & 3756 & $\mathrm{~L}$ & $\mathrm{X} 4$ \\
\hline 31 & SBN & 3759 & $P$ & $\mathrm{X} 4$ \\
\hline 32 & SKR & 3761 & $\mathrm{~L}$ & $\mathrm{X} 4$ \\
\hline 33 & UN & 3749 & $\mathrm{~L}$ & $\mathrm{X} 4$ \\
\hline
\end{tabular}

10 


\begin{tabular}{|c|l|r|r|c|}
\hline 34 & WH & 3753 & $\mathrm{P}$ & $\mathrm{X} 4$ \\
\hline 35 & NJH & 3774 & $\mathrm{P}$ & $\mathrm{X} 4$ \\
\hline
\end{tabular}

\section{Sumber data: SMAN 2 Kota Bima}

Berikut ini dikemukakan data hasil angket tentang pengaruh bimbingan kelompok yang tercantum dalam tabel 4.2 yang dalam tabel di bawah ini hanya akan dicantumkan berdasarkan pilihan jawaban siswa sampel penelitian sebanyak 35 orang siswa namun data pada tabel 4.2 telah diacak dan diberikan kode, hal ini mengingat data siswa sampel penelitian yang harus dirahasiakan.

Tabel 4.2 Data kriteria hasil Angket tentang bimbingan kelompok pada siswa SMAN 2 Kota Bima tahun pelajaran 2016/2017

\begin{tabular}{|c|c|c|c|c|c|c|c|c|c|c|c|}
\hline \multirow{2}{*}{ No } & \multirow{2}{*}{ Kode Nama Siswa } & \multicolumn{10}{|c|}{ Angket nomor } \\
\hline & & 1 & 2 & 3 & 4 & 5 & 6 & 7 & 8 & 9 & 10 \\
\hline 1 & WHr & 1 & 3 & 5 & 5 & 4 & 4 & 3 & 4 & 4 & 1 \\
\hline 2 & NRs & 1 & 2 & 5 & 4 & 3 & 3 & 3 & 2 & 1 & 4 \\
\hline 3 & Ary & 1 & 2 & 5 & 3 & 3 & 1 & 3 & 3 & 2 & 1 \\
\hline 4 & NR & 1 & 4 & 2 & 4 & 3 & 3 & 1 & 1 & 2 & 1 \\
\hline 5 & DDs & 1 & 3 & 5 & 4 & 3 & 1 & 1 & 3 & 2 & 1 \\
\hline 6 & Syk & 1 & 3 & 5 & 3 & 3 & 1 & 1 & 3 & 1 & 1 \\
\hline 7 & RD & 1 & 2 & 5 & 4 & 3 & 1 & 3 & 3 & 2 & 1 \\
\hline 8 & ASW & 1 & 2 & 5 & 5 & 3 & 4 & 3 & 3 & 2 & 1 \\
\hline 9 & Fmy & 1 & 4 & 5 & 3 & 3 & 1 & 1 & 3 & 2 & 1 \\
\hline 10 & FIs & 1 & 3 & 5 & 5 & 4 & 3 & 3 & 4 & 2 & 1 \\
\hline 11 & Fta & 1 & 2 & 5 & 5 & 4 & 3 & 4 & 3 & 2 & 2 \\
\hline 12 & $\mathrm{SMb}$ & 2 & 5 & 5 & 5 & 1 & 3 & 5 & 3 & 5 & 1 \\
\hline 13 & Ikp & 2 & 2 & 5 & 5 & 3 & 3 & 5 & 3 & 4 & 1 \\
\hline
\end{tabular}




\begin{tabular}{|c|c|c|c|c|c|c|c|c|c|c|c|}
\hline 14 & Jni & 2 & 2 & 5 & 5 & 4 & 3 & 1 & 3 & 1 & 1 \\
\hline 15 & JRd & 1 & 2 & 5 & 5 & 2 & 1 & 3 & 3 & 2 & 1 \\
\hline 16 & $\mathrm{RF}$ & 1 & 2 & 3 & 1 & 3 & 1 & 3 & 1 & 1 & 1 \\
\hline 17 & KRt & 1 & 2 & 5 & 5 & 4 & 3 & 4 & 3 & 2 & 2 \\
\hline 18 & SJW & 1 & 4 & 5 & 3 & 3 & 1 & 3 & 3 & 1 & 4 \\
\hline 19 & $\mathrm{Rad}$ & 1 & 2 & 5 & 5 & 3 & 3 & 3 & 3 & 2 & 1 \\
\hline 20 & FRY & 1 & 2 & 5 & 5 & 1 & 3 & 1 & 2 & 2 & 2 \\
\hline 21 & UM & 1 & 2 & 5 & 4 & 1 & 1 & 1 & 1 & 1 & 1 \\
\hline 22 & Irh & 1 & 3 & 5 & 5 & 4 & 1 & 3 & 3 & 2 & 1 \\
\hline 23 & $\mathrm{NJ}$ & 1 & 4 & 5 & 5 & 3 & 3 & 3 & 3 & 1 & 1 \\
\hline 24 & Abw & 1 & 2 & 5 & 5 & 4 & 1 & 1 & 2 & 1 & 1 \\
\hline 25 & ANs & 1 & 2 & 5 & 5 & 3 & 1 & 1 & 1 & 2 & 1 \\
\hline 26 & Dwy & 1 & 4 & 4 & 2 & 3 & 1 & 4 & 3 & 5 & 5 \\
\hline 27 & Fhy & 1 & 2 & 5 & 5 & 4 & 3 & 4 & 4 & 1 & 2 \\
\hline 28 & $\mathrm{KFq}$ & 1 & 3 & 3 & 5 & 1 & 1 & 3 & 2 & 1 & 2 \\
\hline 29 & SRl & 1 & 2 & 2 & 5 & 1 & 1 & 1 & 1 & 1 & 2 \\
\hline 30 & $\mathrm{MFc}$ & 1 & 1 & 3 & 3 & 5 & 1 & 1 & 3 & 3 & 1 \\
\hline 31 & $\mathrm{MRd}$ & 1 & 3 & 5 & 5 & 4 & 1 & 1 & 3 & 1 & 1 \\
\hline 32 & MSh & 4 & 2 & 5 & 5 & 3 & 1 & 1 & 3 & 1 & 1 \\
\hline 33 & $\mathrm{MMr}$ & 1 & 2 & 5 & 2 & 3 & 1 & 1 & 1 & 2 & 1 \\
\hline 34 & $\mathrm{MMz}$ & 1 & 3 & 5 & 5 & 3 & 1 & 1 & 3 & 2 & 1 \\
\hline 35 & $\mathrm{NGt}$ & 4 & 5 & 5 & 5 & 3 & 1 & 1 & 3 & 1 & 1 \\
\hline
\end{tabular}

Sumber Data: Hasil Olahan

Selanjutnya masalah data motivasi belajar siswa tercantum dalam tabel 4.3 sebagai berikut: 
Tabel 4.3 Data kriteria hasil angket tentang motivasi belajar pada siswa SMAN 2 Kota Bima tahun pelajaran 2016/2017

\begin{tabular}{|c|c|c|c|c|c|c|c|c|c|c|c|}
\hline \multirow{2}{*}{ No } & \multirow{2}{*}{ Kode Nama Siswa } & \multicolumn{10}{|c|}{ Angket nomor } \\
\hline & & 1 & 2 & 3 & 4 & 5 & 6 & 7 & 8 & 9 & 10 \\
\hline 1 & WHr & 5 & 3 & 4 & 2 & 5 & 3 & 3 & 4 & 4 & 4 \\
\hline 2 & NRs & 4 & 2 & 2 & 2 & 2 & 2 & 3 & 3 & 4 & 4 \\
\hline 3 & Ary & 4 & 3 & 5 & 2 & 4 & 3 & 1 & 3 & 4 & 4 \\
\hline 4 & NR & 5 & 3 & 5 & 1 & 1 & 2 & 4 & 2 & 4 & 1 \\
\hline 5 & DDs & 4 & 2 & 2 & 2 & 4 & 2 & 2 & 3 & 4 & 4 \\
\hline 6 & Syk & 4 & 3 & 2 & 2 & 4 & 2 & 4 & 4 & 4 & 4 \\
\hline 7 & $\mathrm{RD}$ & 4 & 2 & 2 & 2 & 4 & 2 & 3 & 3 & 4 & 4 \\
\hline 8 & ASW & 4 & 3 & 5 & 2 & 4 & 2 & 5 & 3 & 4 & 4 \\
\hline 9 & Fmy & 4 & 2 & 5 & 2 & 4 & 3 & 4 & 5 & 4 & 4 \\
\hline 10 & FIs & 4 & 3 & 2 & 2 & 4 & 5 & 4 & 4 & 4 & 4 \\
\hline 11 & $\mathrm{Fta}$ & 5 & 3 & 2 & 2 & 4 & 2 & 4 & 4 & 4 & 4 \\
\hline 12 & $\mathrm{SMb}$ & 4 & 3 & 5 & 1 & 3 & 5 & 3 & 5 & 4 & 4 \\
\hline 13 & Ikp & 5 & 3 & 4 & 4 & 2 & 4 & 5 & 5 & 4 & 4 \\
\hline 14 & Jni & 4 & 3 & 5 & 2 & 3 & 2 & 3 & 2 & 4 & 4 \\
\hline 15 & $\mathrm{JRd}$ & 5 & 3 & 2 & 4 & 3 & 2 & 5 & 5 & 4 & 4 \\
\hline 16 & $\mathrm{RF}$ & 5 & 3 & 5 & 5 & 4 & 5 & 4 & 5 & 4 & 4 \\
\hline 17 & KRt & 4 & 3 & 5 & 2 & 3 & 2 & 3 & 2 & 4 & 4 \\
\hline 18 & SJw & 4 & 2 & 4 & 4 & 2 & 2 & 3 & 3 & 4 & 4 \\
\hline 19 & $\operatorname{Rad}$ & 1 & 3 & 4 & 2 & 2 & 3 & 4 & 3 & 4 & 2 \\
\hline 20 & FRY & 4 & 2 & 2 & 4 & 4 & 2 & 4 & 4 & 4 & 3 \\
\hline
\end{tabular}




\begin{tabular}{|c|l|c|c|c|c|c|c|c|c|c|c|}
\hline 21 & UM & 5 & - & 2 & 2 & 4 & 2 & 3 & 4 & 4 & 4 \\
\hline 22 & Irh & 4 & 1 & 4 & 4 & 3 & 2 & 4 & 4 & 4 & 3 \\
\hline 23 & NJ & 4 & 3 & 4 & 4 & 4 & 2 & 4 & 4 & 4 & 1 \\
\hline 24 & Abw & 2 & 3 & 5 & 2 & 3 & 2 & 4 & 4 & 4 & 4 \\
\hline 25 & ANs & 4 & 3 & 2 & 2 & 3 & 2 & 2 & 3 & 4 & 4 \\
\hline 26 & Dwy & 4 & 3 & 2 & 2 & 4 & 3 & 4 & 2 & 4 & 4 \\
\hline 27 & Fhy & 5 & 3 & 2 & 1 & 4 & 2 & 4 & 4 & 4 & 1 \\
\hline 28 & KFq & 4 & 3 & 5 & 4 & 4 & 2 & 3 & 4 & 4 & 4 \\
\hline 29 & SRl & 4 & 3 & 4 & 2 & 5 & 2 & 3 & 3 & 4 & 4 \\
\hline 30 & MFc & 1 & 5 & 4 & 2 & 2 & 3 & 4 & 5 & 4 & 4 \\
\hline 31 & MRd & 5 & 3 & 4 & 4 & 5 & 3 & 4 & 3 & 4 & 3 \\
\hline 32 & MSh & 5 & 3 & 2 & 2 & 4 & 2 & 3 & 4 & 4 & 4 \\
\hline 33 & MMr & 4 & 3 & 4 & 2 & 3 & 2 & 1 & 3 & 4 & 4 \\
\hline 34 & MMz & 5 & 3 & 2 & 4 & 4 & 5 & 5 & 5 & 4 & 3 \\
\hline 35 & NGt & & 3 & 4 & 4 & 5 & 5 & 1 & 2 & 4 & 4 \\
\hline
\end{tabular}

Sumber Data: Hasil Olahan

Sebelum dilakukan analisis data maka dari data pada tabel 4.2 dan tabel 4.3 diadakan penganalisaan dengan menggunakan tabel berikut:

Tabel 4.4 Persiapan Analisis Data

\begin{tabular}{|c|l|c|c|c|c|c|}
\hline No & \multicolumn{1}{|c|}{ Kode Nama Siswa } & X & Y & $\mathbf{X}^{2}$ & $\mathbf{Y}^{2}$ & XY \\
\hline 1 & WHr & 34 & 37 & 1156 & 1369 & 1258 \\
\hline 2 & NRs & 28 & 28 & 784 & 784 & 784 \\
\hline 3 & Ary & 24 & 33 & 576 & 1089 & 792 \\
\hline
\end{tabular}




\begin{tabular}{|c|c|c|c|c|c|c|}
\hline 4 & NR & 22 & 28 & 484 & 784 & 616 \\
\hline 5 & DDs & 24 & 29 & 576 & 841 & 696 \\
\hline 6 & Syk & 22 & 33 & 484 & 1089 & 726 \\
\hline 7 & $\mathrm{RD}$ & 25 & 30 & 625 & 900 & 750 \\
\hline 8 & ASW & 29 & 36 & 841 & 1296 & 1044 \\
\hline 9 & Fmy & 24 & 37 & 576 & 1369 & 888 \\
\hline 10 & FIs & 31 & 36 & 961 & 1296 & 1116 \\
\hline 11 & Fta & 31 & 34 & 961 & 1156 & 1054 \\
\hline 12 & $\mathrm{SMb}$ & 35 & 37 & 1225 & 1369 & 1295 \\
\hline 13 & Ikp & 33 & 40 & 1089 & 1600 & 1320 \\
\hline 14 & Jni & 27 & 32 & 729 & 1024 & 864 \\
\hline 15 & $\mathrm{JRd}$ & 25 & 37 & 625 & 1369 & 925 \\
\hline 16 & RF & 17 & 44 & 289 & 1936 & 748 \\
\hline 17 & KRt & 31 & 32 & 961 & 1024 & 992 \\
\hline 18 & SJw & 28 & 32 & 784 & 1024 & 896 \\
\hline 19 & $\mathrm{Rad}$ & 28 & 28 & 784 & 784 & 784 \\
\hline 20 & FRY & 24 & 33 & 576 & 1089 & 792 \\
\hline 21 & UM & 18 & 30 & 324 & 900 & 540 \\
\hline 22 & Irh & 28 & 33 & 784 & 1089 & 924 \\
\hline 23 & NJ & 29 & 34 & 841 & 1156 & 986 \\
\hline 24 & Abw & 23 & 33 & 529 & 1089 & 759 \\
\hline 25 & ANs & 22 & 29 & 484 & 841 & 638 \\
\hline 26 & Dwy & 32 & 32 & 1024 & 1024 & 1024 \\
\hline 27 & Fhy & 31 & 30 & 961 & 900 & 930 \\
\hline
\end{tabular}

15 


\begin{tabular}{|c|l|c|c|c|c|c|}
\hline 28 & $\mathrm{KFq}$ & 22 & 37 & 484 & 1369 & 814 \\
\hline 29 & $\mathrm{SRl}$ & 17 & 34 & 289 & 1156 & 578 \\
\hline 30 & $\mathrm{MFc}$ & 22 & 34 & 484 & 1156 & 748 \\
\hline 31 & $\mathrm{MRd}$ & 25 & 38 & 625 & 1444 & 950 \\
\hline 32 & $\mathrm{MSh}$ & 26 & 33 & 676 & 1089 & 858 \\
\hline 33 & $\mathrm{MMr}$ & 19 & 30 & 361 & 900 & 570 \\
\hline 34 & $\mathrm{MMz}$ & 25 & 40 & 625 & 1600 & 1000 \\
\hline 35 & $\mathrm{NGt}$ & 29 & 36 & 841 & 1296 & 1044 \\
\hline & & 910 & 1179 & 24418 & 40201 & 30703 \\
\hline & & 26,00 & 33,69 & & & \\
\hline
\end{tabular}

Dari data pada tabel tersebut di atas maka akan dimasukan dalam rumus regresi linear sederhana sebagai berikut:

$$
Y=a+b x
$$

Namun sebelum itu terlebih dahulu akan dicari nilai a dan b dengan menggunakan rumus sebagai berikut:

$$
\begin{aligned}
& b=\frac{n \Sigma X Y-n \cdot \bar{X} \cdot \bar{Y}}{\Sigma X^{2}-n \cdot \bar{X}} \\
& b=\frac{35.30703-35.26,00.33,69}{24418-35.26,00} \\
& b=\frac{107460-30654}{24418-910}
\end{aligned}
$$


$b=\frac{76806}{23508}$

$b=3,27$

Setelah nilai b diketahui, langkah berikutnya mencari nilai dari a dengan rumus sebagai berikut:

$$
\begin{aligned}
& a=\bar{Y}-b \cdot \bar{X} \\
& a=33,69-3,27.26,00 \\
& a=33,69-84,95 \\
& a=-51,26
\end{aligned}
$$

Nilai a dan b dimasukan ke dalam rumus regresi sederhana sebagai berikut:

$$
\begin{aligned}
& Y=a+b x \\
& Y=33,196+(-51,26) x \\
& Y=33,196-51,26 x
\end{aligned}
$$

Dari data tersebut di atas maka dapat disimpulkan bahwa layanan bimbingan kelompok dalam hal mengontrol dan membina tingkah laku pada anak baik menyangkut kewajiban anak melaksanakan belajar, kewajiban anak untuk sekolah mengaji, nasehat-nasehat yang tidak jauh dari ajaran agama islam, tuntutan agar anak selalu berpendidikan, ganjaran bagi anak yang tidak melaksanakan perintah orang tua maupun guru, taat kepada orang tua dapat digolongkan dalam posisi yang sangat baik akan sangat mendukung tumbuhnya motivasi belajar siswa di Kelas X SMAN 2 Kota Bima tahun pelajaran 2016/2017. Dan hubungan antara kedua variabel adalah, yang menandakan bahwa ada pengaruh dasar 
layanan bimbingan kelompok dengan motivasi belajar siswa X SMAN 2 Kota Bima tahun pelajaran 2016/2017 ke arah yang lebih baik.

\section{KESIMPULAN}

Berdasarkan uraian dari hasil analisis data maka dapat disimpulkan bahwa:

1. Hasil wawancara dan observasi selama penelitian dilaksanakan diperoleh kesimpulan bahwa ada pengaruh bimbingan kelompok terhadap motivasi belajar siswa di SMAN 2 KotaBima Tahun Pelajaran 2016/2017,

2. Hal ini dibuktikan dari hasil analisis data menggunakan analisis regresi yang menandakan hubungan antara kedua variabel yang terlibat adalah positif dengan $\mathrm{Y}=33,196-51,26 x$ yang artinya antara kedua variabel yang terlibat berhubungan positif.

\section{Saran}

Berdasarkan kesimpulan yang diambil tersebut maka disarankan kepada:

1. Siswa-siswi SMAN 2 Kota Bima untuk lebih meningkatkan prestasi belajarnya, karena salah satu faktor pendukung yang dapat mempengaruhi tingkat motivasi belajar siswa adalah prestasi belajar atau pendidikan yang dimiliki seseorang.

2. Orangtua dari siswa-siswi SMAN 2 Kota Bima untuk lebih menghargai pendapat dan ide serta pemikiran anak-anaknya agar anak-anaknya merasa bahwa dari dalam keluarga dia telah diakui bahwa dirinya telah memiliki kelebihan dalam mengungkapkan ide, pemikiran dan sebagainya.

3. Guru-Guru SMAN 2 Kota Bima agar memberikan kesempatan yang sama kepada siswasiswinya untuk mengungkapkan pendapat dan memberikan penghargaan terhadap ide dan 
pendapat tersebut agar anak terbiasa untuk berbicara didepan umum seningga dengan sendirinya akan meningkatkan motivasi belajar anak.

\section{DAFTAR RUJUKAN}

Ahmadi, A. 1990. Psikologi Sosial. Jakarta: Rineka Cipta.

Andayani, B; Afiatin, T. 1996. Konsep Diri, Harga Diri dan Kepercayaan Diri Remaja. Jurnal Psikologi. Yogyakarta: Fakultas Psikologi Universitas Gajah Mada.

Anthony, 1996 Rahasia Membangun Kepercayaan Diri, Alih Bahasa: Wiryadi, R. Jakarta: Bina Rupa Aksara.

Arikunto, Suharsimin. 1997. Prosedur Penelitian. Jakarta: Rineka Cipta.

Azwar, S. 1989. Reliabilitas dan Validitas. Yogyakarta: Pustaka Pelajar

Brewer, Hartley E., 2000. Menumbuhkan Rasa Percaya Diri Pada Anak. Jakarta : Gramedia.

Daradjat, Z. 1990. Kesehatan Mental. Jakarta: CV. Haji Masagung.

Dargatz, 1999. 52 Cara Membangun Harga Diri dan Percaya Diri Anak. Jakarta : Pustaka Tangga.

Djauharah Bawazir.1993. Partisipasi Masyarakat pada Pendidikan Anak dalam Keluarga. Unsocial-Learning.Blogspot.Com

Elly Risman. 2003. Biarkan Anak Bicara. Jakarta: CV. Haji Masagung.

Gerungan, W. A. 2004. Psikologi Sosial. Bandung: Rafika Aditama

Gunawan. 2000. Kebijakan Pendidikan di Indonesia, Jakarta: Penerbit Aksara.

Hakim, T. 2002. Mengatasi Rasa Tidak Percaya Diri. Jakarta: Puspa Swara.

Loekmono, L. 1983. Rasa Percaya Diri Sendiri. Salatiga: Pusat Bimbingan Universitas Kristen Satya Wacana.

Martani W.; Adiyanti M.G., 1991. Kompetensi Sosial dan Kepercayaan Diri Remaja. Jurnal Psikologi, Tahun ke XVIII Nomor 1 Page 17-20.

Monks, F.J; Knoers, A.M.P; Haditono S.R. 1994. Psikologi Perkembangan: Pengantar dalam berbagai bagiannya. Yogyakarta: Gajah Mada University Press 
Ramdhani, N. 1991. Harga Diri dan Tingkat Kecemasan pada Mahasiswa yang sulit bergaul. Laporan Penelitian. Yogyakarta: Fakultas Psikologi Universitas Gajah Mada.

Respatiningsih, Dyah N, 2004. Peranan Orang Tua Dalam Mengembangkan Kepercayaan Diri Pada Anak Prasekolah. Semarang : Tugas Akhir

Supratiknya, A. 1995. Komunikasi tinjauan Psikologis. Yogyakarta: Kanisius.

Santrock, J. W. 1995. Life Span Development. Alih Bahasa: Juda Damanil dan Achmad Chusaisi. Jakarta: Erlangga.

Suryabrata, S. 1984. Psikologi Pendidikan. Jakarta: CV. Rajawali.

Sudjana. 1996. Metode Statistika. Bandung: Tarsito.

Surachmad, Winarno. 1976. Metodologi Research. Andi Ofset : Yogyakarta.

Sudijono, 1991. Penelitian Dan Penilaian Pendidikan. Bandung: Sinar Baru.

Satriadarma, 2001. Persepsi Orang tua membentuk perilaku Anak. Jakarta : Pustaka Populer 